\title{
NUMERICAL INVESTIGATIONS OF NOVEL HIGH-GAIN CIRCULARLY-POLARIZED HYBRID ANTENNA FOR MILLIMETER-WAVE DETECTION AND IMAGING APPLICATIONS
}

\author{
O. M. Haraz \\ Electrical Engineering Department, Faculty of Engineering, Assiut University, Assiut \\ 71515, Arab Republic of Egypt, E-mail: osama.haraz@eng.au.edu.eg
}

Received 16 February, accepted 23 March 2013

\begin{abstract}
A new improved high gain circularly-polarized antenna for millimeter-wave (MMW) applications is introduced in this paper. The proposed antenna consists of a microstrip rectangular patch radiator with corner-chopped fed by a rectangular aperture in the ground plane. To increase the antenna gain, a hollow rectangular ring dielectric resonator (DR) is installed. The DR and microstrip patch radiator together become as a single antenna element with increased gain. Extensive parametric studies are performed to address the effect of varying the antenna parameters on the operational frequency bandwidth. For further gain enhancement, a hemi-spherical dielectric lens made of highdielectric constant is installed above the proposed antenna. Simulated results using Computer System Technology Microwave Studio (CST MWS) software programs based on finite integral numerical modeling technique (FIT) have been presented. The proposed novel antenna is considered a good candidate for circularly-polarized and high gain MMW applications for microwave detection and imaging applications.
\end{abstract}

\section{Introduction}

Millimeter-Wave (MMW) technology is considered as a new emerging technology for the next generation of the wireless networks and for short distance data transfer between the electronic devices. However, MMW communications at frequencies around $60 \mathrm{GHz}$ suffer from high propagation losses due to absorption by oxygen molecules in the atmosphere [1], so high gain is considered as one of the most important issue in antenna design for such frequencies. Also, a circular polarized (CP) antenna is required to assure high quality transmission or reception in order to overcome multi-path, improper line-of-Sight (LOS) between the transmitter and the receiver and some phasing issues due to rain or snow in the air. Recently, many researchers are working on developing high-gain antennas for various applications using printed circuit microstrip technology [2]-[8]. The gain enhancement can be achieved using array principle. In that case, the antenna will have big size and complex structure because of using feed network to feed the antenna elements. There are some techniques have been presented to enhance the gain along with keeping the overall antenna size within acceptable limits. Hybrid antenna has attracted many people and is considered a good solution for improving the antenna characteristics. In hybrid antennas, multiple antennas are excited together with the same or different modes over the same frequency range of operation.

In this paper, we present a novel high-gain circularly-polarized hybrid antenna for MMW detection and imaging applications. The proposed hybrid antenna consists of a microstrip rectangular patch with chopped corners and a hollow rectangular ring dielectric resonator (DR) radiator are working together as a single antenna element fed by a rectangular aperture in the ground plane. Extensive parametric studies to address the effect of varying the antenna

Journal of Engineering Sciences, Assiut University, Faculty of Engineering, Vol. 41, No. 3, May, 2013, E-mail address: jes@aun.edu.eg 
O. M. Haraz, Numerical investigations of novel high-gain circularly-polarized hybrid antenna for millimeter-wave detection and imaging applications, pp. $1078-1100$

parameters on the operational frequency bandwidth are introduced. For further gain and radiation characteristics enhancement, a hemi-spherical dielectric lens made of high-dielectric constant, $\varepsilon_{r}=$ 10.2, is installed above the proposed antenna. The simulated results using the Computer System Technology Microwave Studio ready-made software (CST MWS) [9] are presented and discussed. Finally, the conclusions are summarized in the last Section.

\section{Novel high-gain antenna configurations}

Figure 1 shows the geometry of the conventional corner-chopped circularly-polarized patch antenna [3]. The corner-chopped patch is printed on a low-permittivity $\left(\varepsilon_{r 2}=2.2\right)$ grounded substrate with thickness $h_{2}=0.254-\mathrm{mm}$. The patch is fed by a $50 \Omega$ microstrip line on the backside of a second dielectric layer with a higher permittivity $\left(\varepsilon_{r l}=10.2\right)$ and a thickness $h_{l}=$ $0.254-\mathrm{mm}$. The feeding is achieved through a rectangular aperture $\left(W_{S} \times L_{S}\right)$ etched in the ground plane with a width nearly equals to half-wavelength, i.e. $L_{S}=\lambda / 2$ of the center frequency around $60 \mathrm{GHz}$.

The geometry of proposed hybrid patch dielectric resonator (DR) antenna is shown in Figure 2 . For that geometry, the patch feeds a high-permittivity $\left(\varepsilon_{r 3}=10.2\right)$ hollow rectangular DR radiator with thickness $h_{3}=0.635-\mathrm{mm}$, exciting a higher order hybrid mode $\left(\mathrm{HEM}_{15 \delta}\right)$ which is responsible for gain enhancement of the antenna [2]. This mode increases the overall electrical size of the antenna and increases the gain without array need. The chopped patch corners and the DR corners are the reason for obtaining circular polarization $(\mathrm{CP})$ which can be controlled to be left hand $(\mathrm{LH})$ or right hand $(\mathrm{RH})$ by changing the chopped corners of both the patch and the DR to the opposite sides [3]. The effect of antenna parameters on its performance is also studied.

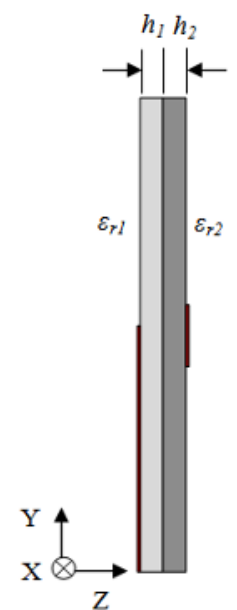

(a)

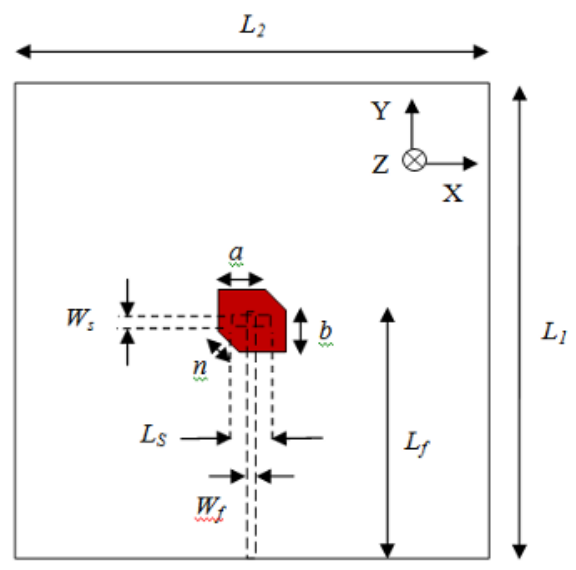

(b)

Fig. 1. Geometry of conventional corner-chopped circularly-polarized patch antenna (a) side view (b) top view.

Journal of Engineering Sciences, Assiut University, Faculty of Engineering, Vol. 41, No. 3, May, 2013,E-mail address: jes@aun.edu.eg 


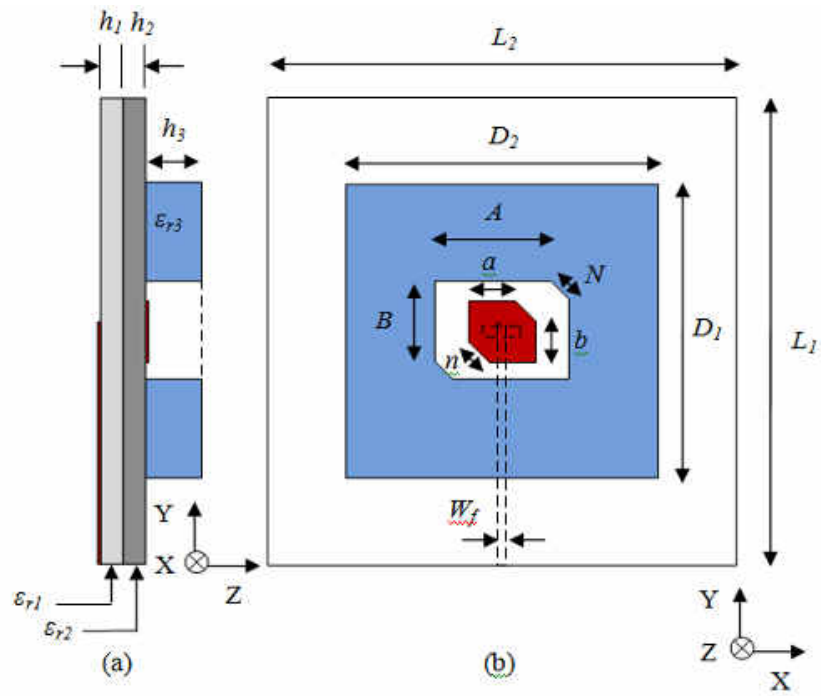

Fig. 2. Geometry of high-gain circularly-polarized hybrid antenna (a) side view (b) top view.

\section{Parametric studies}

Extensive parametric studies have been carried out to address the effect of antenna physical parameters on its performance such as the antenna operation bandwidth. This happen by varying one antenna parameter with keeping all other parameters fixed and plot the antenna reflection coefficient $S_{11}$ curves versus frequency. All parametric studies were performed using Computer Simulation Technology (CST) Microwave Studio (MWS) [9]. All simulation results have been carried out using CST Microwave Studio [9] which solves electromagnetic problems in time-domain using Finite Integral Technique (FIT).

Figure 3 shows the effect of varying the rectangular dielectric resonator (DR) length $D_{1}$ and width $D_{2}$ on the antenna reflection coefficient $S_{11}$. The values of other parameters are kept constant as listed in Table 1. The metal thickness is t. It can be seen that the DR is strongly affects the overall antenna operation bandwidth.

The effect of rectangular DR air groove of length $A$ and width $B$ on the antenna performance is plotted in Figure 4. The values of other parameters are kept constant as listed in Table 1. It can be noticed that the DR air groove controls the impedance matching of the ${ }^{\varepsilon_{r}}$ antenna and hence it affects the overall operation bandwidth of the proposed antenna.

The effect of both the chopped DR corner of length $N$ and the DR height $h_{3}$ on the antenna performance are also studied and shown in Figure 5. The values of other parameters are kept constant as listed in Table 1. There is no much effect for the chopped DR corner length $N$ on the antenna reflection coefficient while it is used for generating circular polarization. On the other hand, the DR height $h_{3}$ is strongly affect the modes of DR and hence controls the antenna bandwidth.

Journal of Engineering Sciences, Assiut University, Faculty of Engineering, Vol. 41, No. 3, May, 2013,E-mail address: jes@aun.edu.eg 
1081

O. M. Haraz, Numerical investigations of novel high-gain circularly-polarized hybrid antenna for millimeter-wave detection and imaging applications, pp. $1078-1100$

Figure $6,7 \& 8$ present the parametric studies to investigate the effect of the other antenna dimensions, such as microstrip rectangular patch length $a$, width $b$, chopped patch corner length n, microstrip feed line length $L_{f}$, rectangular slot length Ls and width $W_{s}$. The microstrip feed line length $L_{f}$ and slot dimensions $\left(L_{s}, W_{s}\right)$ are strongly affecting the antenna matching performance. By controlling those different parameters, wideband antenna behavior can be achieved. All the optimized antenna parameters are shown in Table 1.

Table 1. configurable parameter values for the proposed antenna (units in $\mathrm{mm}$ )

\begin{tabular}{ccccccccc}
\hline \hline Parameter & $\boldsymbol{h}_{\boldsymbol{1}}\left(=\boldsymbol{h}_{2}\right)$ & $\boldsymbol{h}_{3}$ & $\boldsymbol{t}$ & $\boldsymbol{L}_{s}$ & $\boldsymbol{W}_{f}$ & $\boldsymbol{L}_{f}$ & $\boldsymbol{L}_{\boldsymbol{I}}\left(=\boldsymbol{L}_{2}\right)$ \\
\hline Value & 0.254 & 0.635 & 0.035 & 0.85 & 0.185 & 5.45 & 10.5 \\
\hline Parameter & $\boldsymbol{D}_{\boldsymbol{1}}$ & $\boldsymbol{D}_{\mathbf{2}}$ & $\boldsymbol{A}$ & $\boldsymbol{B}$ & $\boldsymbol{a}$ & $\boldsymbol{b}$ & $\boldsymbol{W}_{s}$ & $\boldsymbol{N}(=\boldsymbol{n})$ \\
\hline Value & 7.0 & 6.6 & 2.6 & 1.8 & 1.1 & 0.98 & 0.35 & 0.565 \\
\hline \hline
\end{tabular}

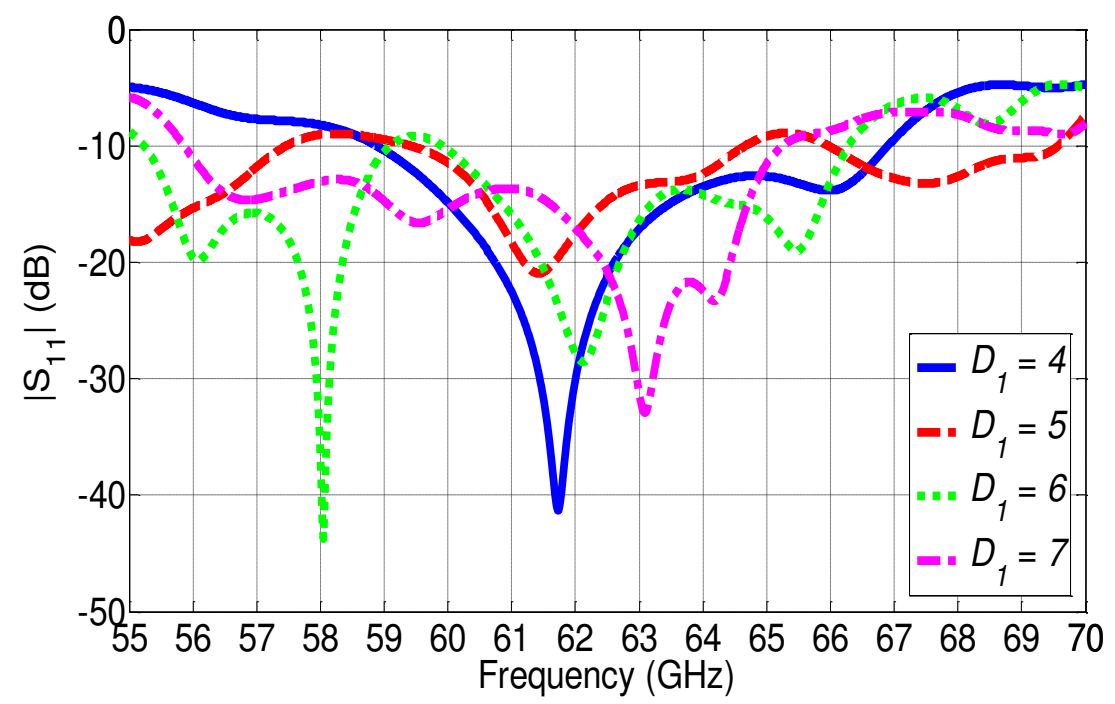

(a)

Journal of Engineering Sciences, Assiut University, Faculty of Engineering, Vol. 41, No. 3, May, 2013,E-mail address: jes@aun.edu.eg 
O. M. Haraz, Numerical investigations of novel high-gain circularly-polarized hybrid antenna for millimeter-wave detection and imaging applications, pp. $1078-1100$

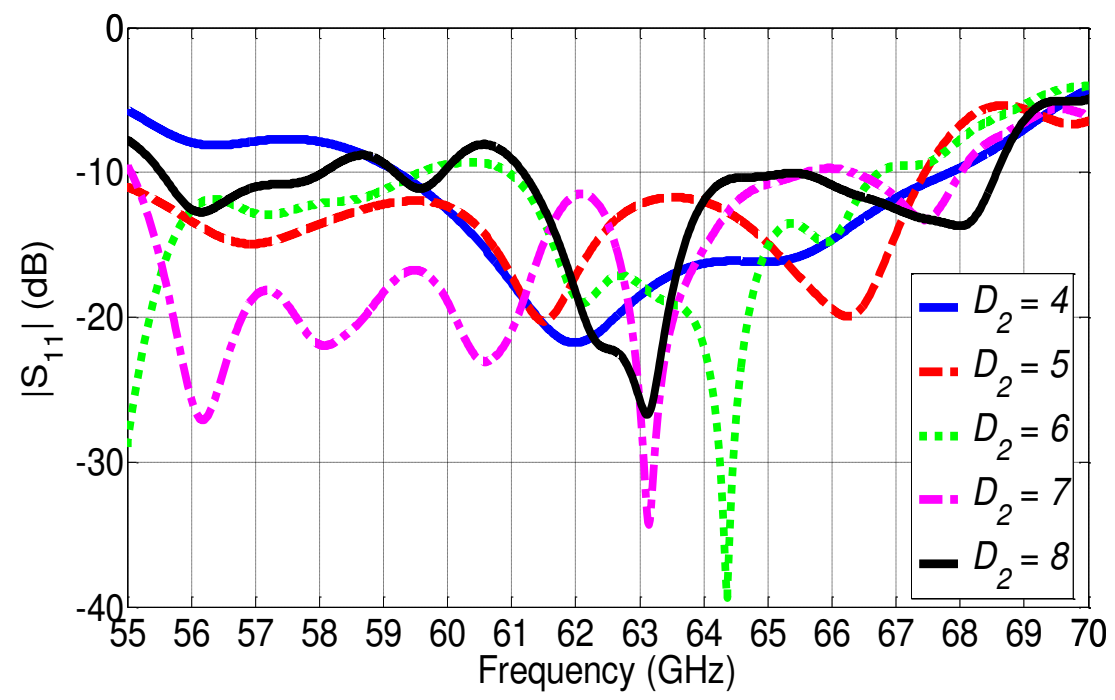

(b)

Fig. 3. Parametric studies on the effect of rectangular dielectric resonator with changing of: (a) length $D_{1}$, and (b) width $D_{2}$

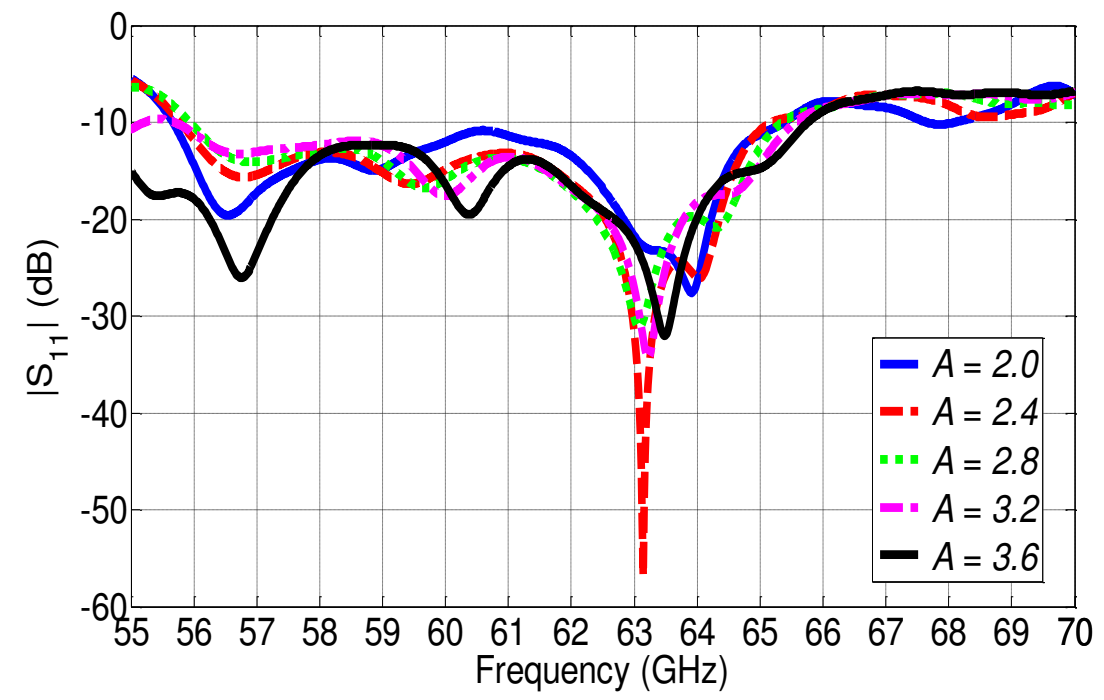

(a)

Journal of Engineering Sciences, Assiut University, Faculty of Engineering, Vol. 41, No. 3, May, 2013,E-mail address: jes@aun.edu.eg 
O. M. Haraz, Numerical investigations of novel high-gain circularly-polarized hybrid antenna for millimeter-wave detection and imaging applications, pp. 1078 - 1100

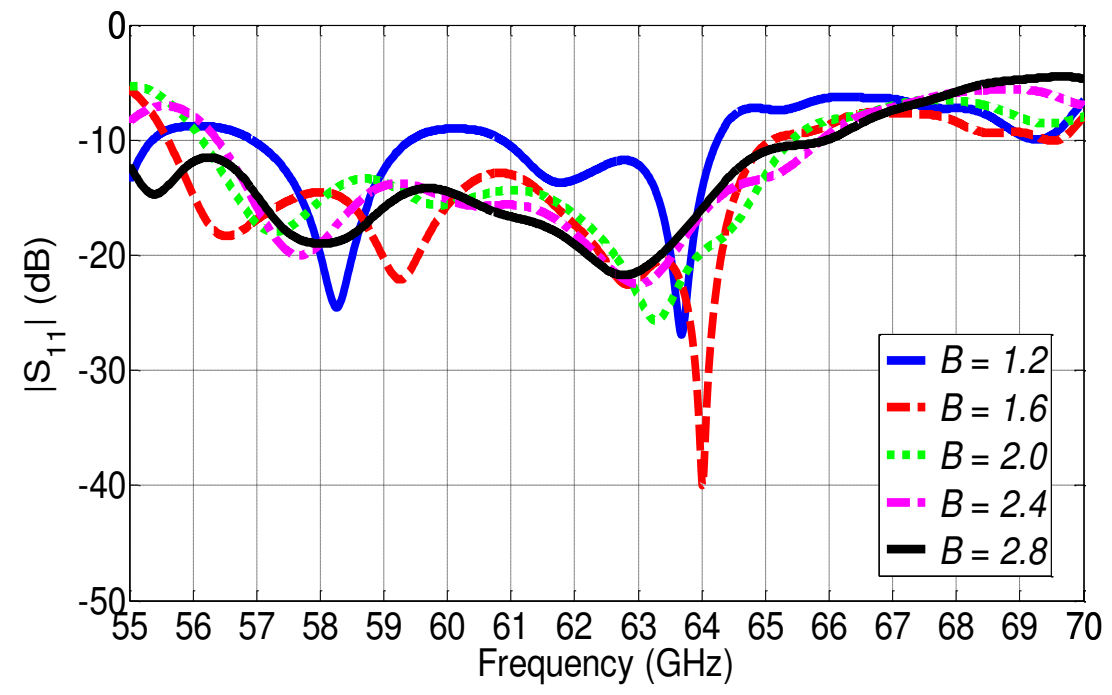

(b)

Fig. 4. Parametric studies on the effect of rectangular DR air groove dimensions, (a) length $A$ and (b) width $B$

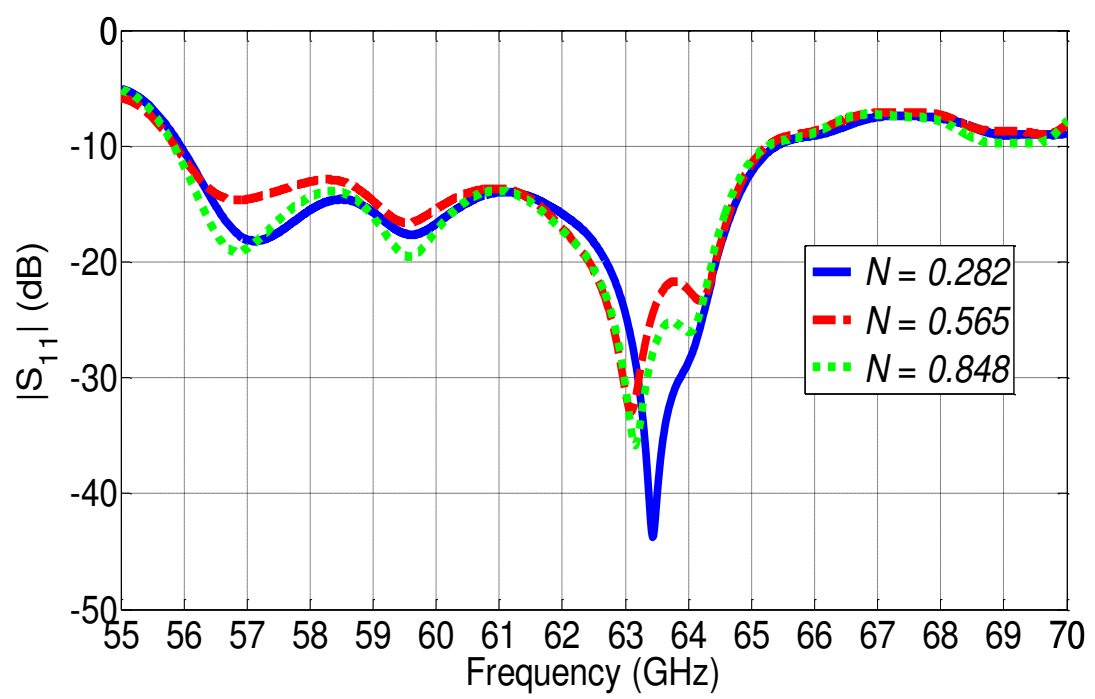

(a)

Journal of Engineering Sciences, Assiut University, Faculty of Engineering, Vol. 41, No. 3, May, 2013, E-mail address: jes@aun.edu.eg 
O. M. Haraz, Numerical investigations of novel high-gain circularly-polarized hybrid antenna for millimeter-wave detection and imaging applications, pp. $1078-1100$

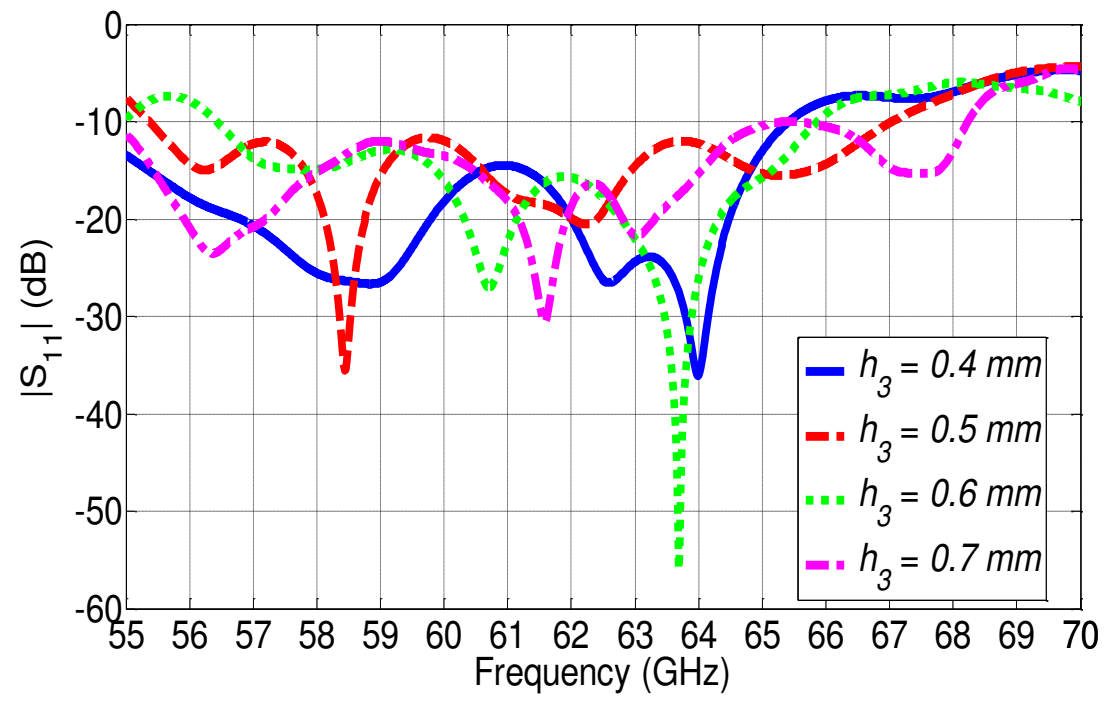

(b)

Fig. 5. Parametric studies on the effect of (a) chopped DR corner dimensions, length $N$ and (b) DR thickness $h_{3}$

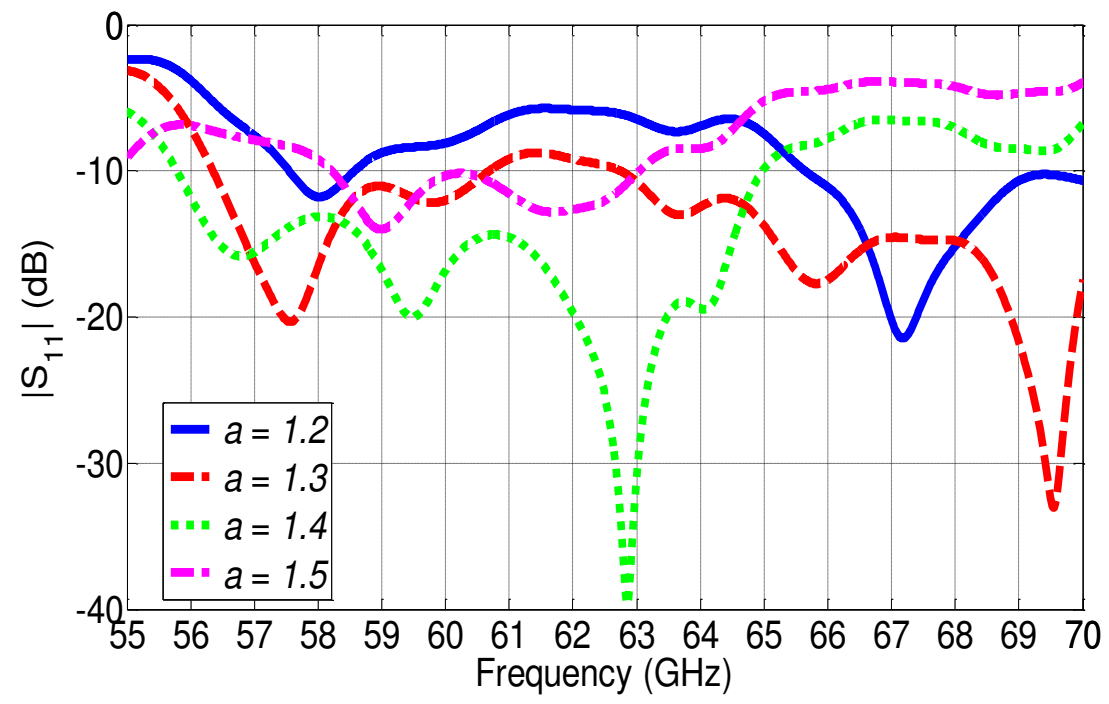

(a)

Journal of Engineering Sciences, Assiut University, Faculty of Engineering, Vol. 41, No. 3, May, 2013, E-mail address: jes@aun.edu.eg 


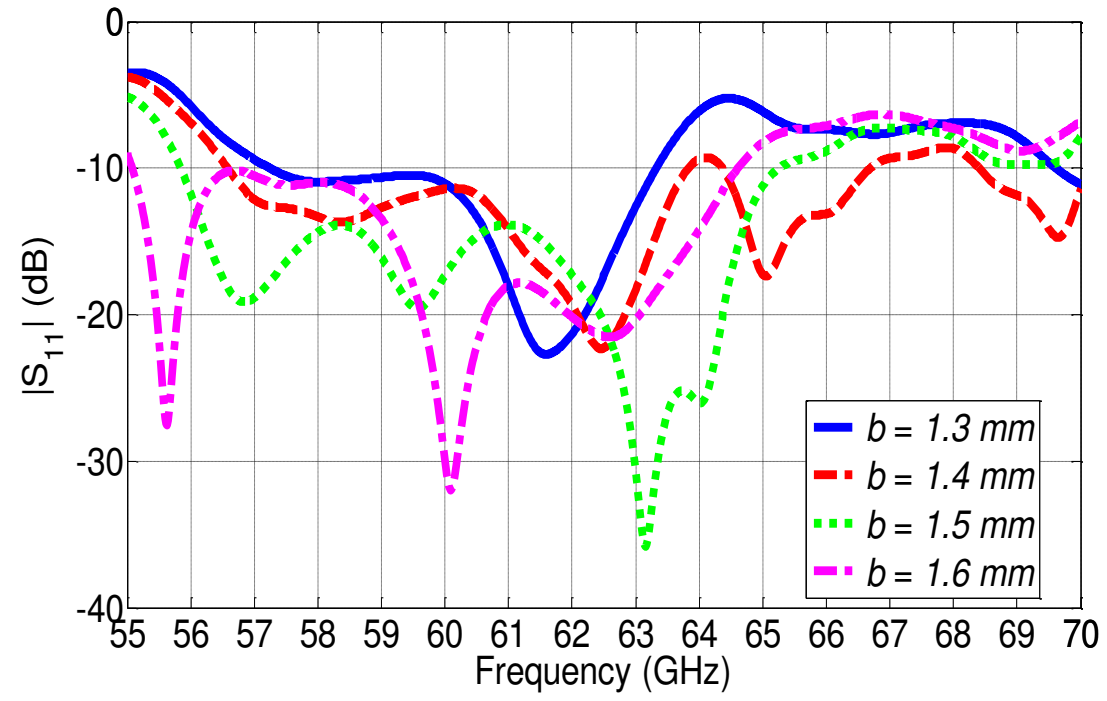

(b)

Fig. 6. Parametric studies on the effect of microstrip rectangular patch dimensions, (a) length $a$ and (b) width $b$

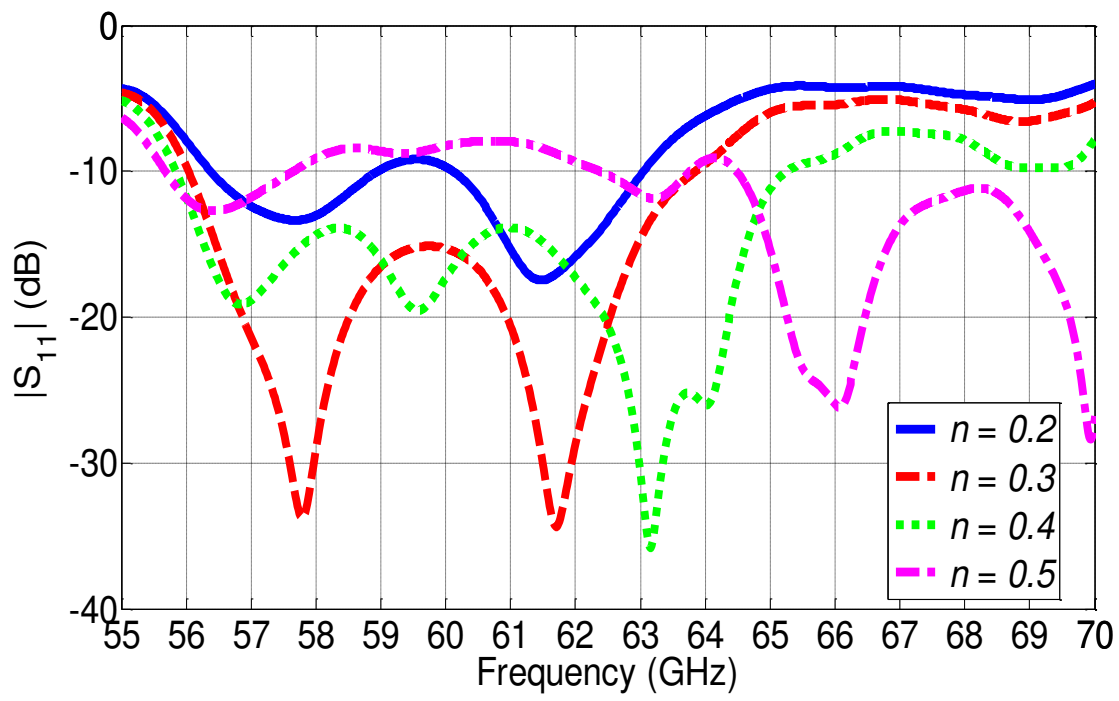

(a)

Journal of Engineering Sciences, Assiut University, Faculty of Engineering, Vol. 41, No. 3, May, 2013,E-mail address: jes@aun.edu.eg 
O. M. Haraz, Numerical investigations of novel high-gain circularly-polarized hybrid antenna for millimeter-wave detection and imaging applications, pp. $1078-1100$

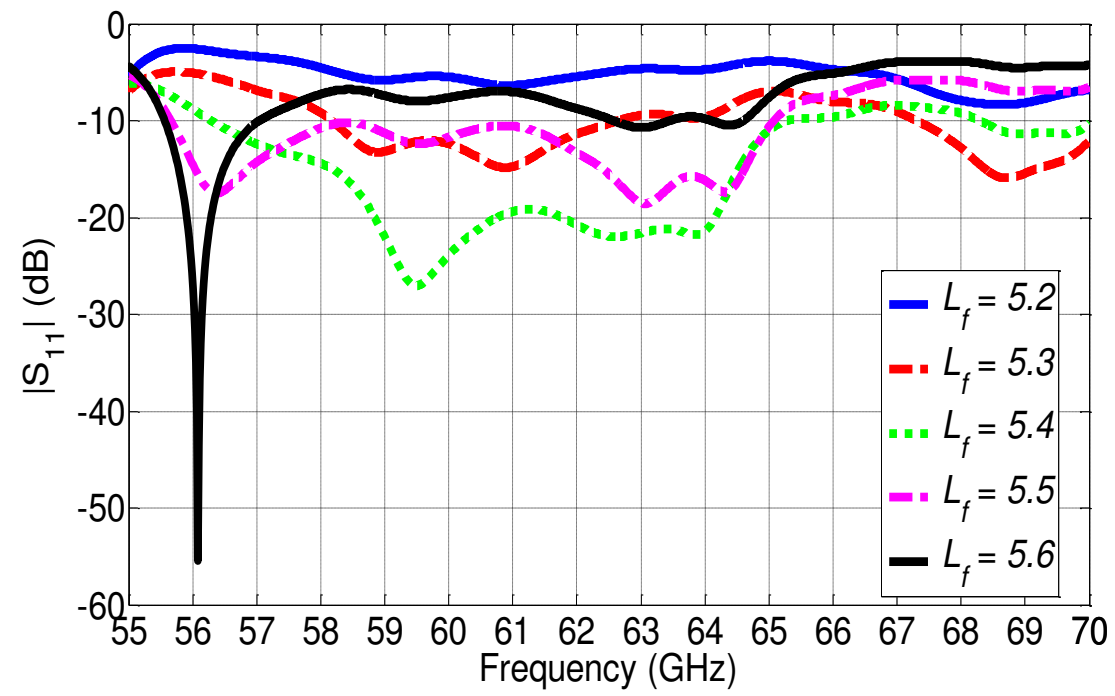

(b)

Fig. 7. Parametric studies on the effect of (a) chopped patch corner length $n$ and (b) microstrip feed line length $L_{f}$

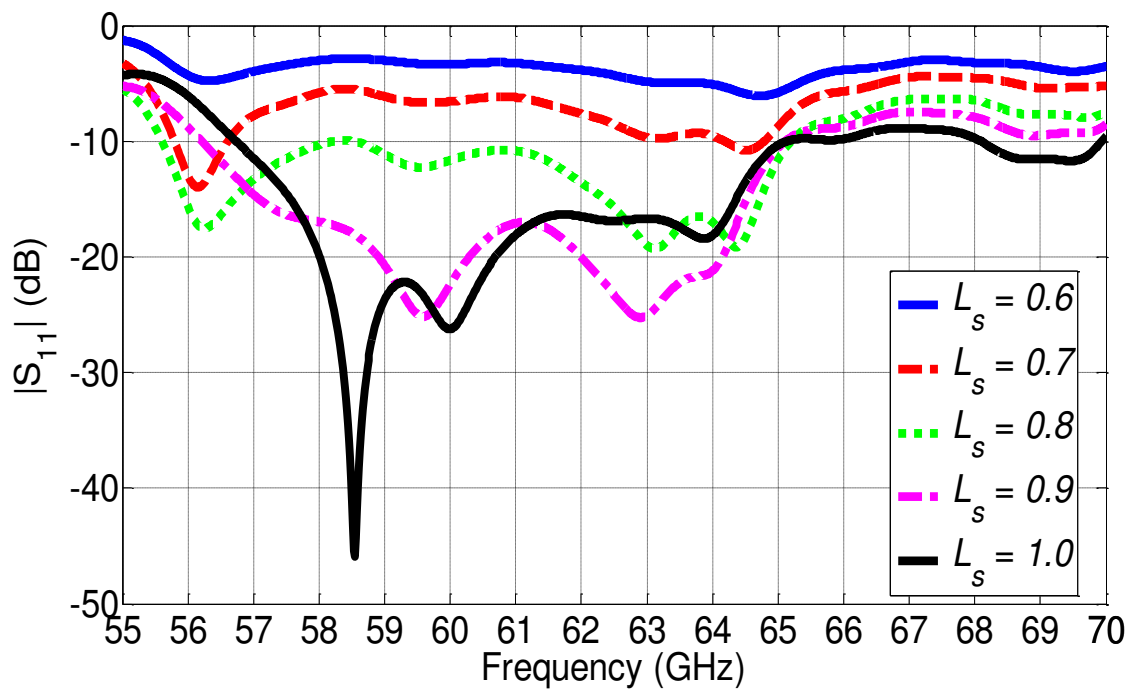

(a)

Journal of Engineering Sciences, Assiut University, Faculty of Engineering, Vol. 41, No. 3, May, 2013,E-mail address: jes@aun.edu.eg 


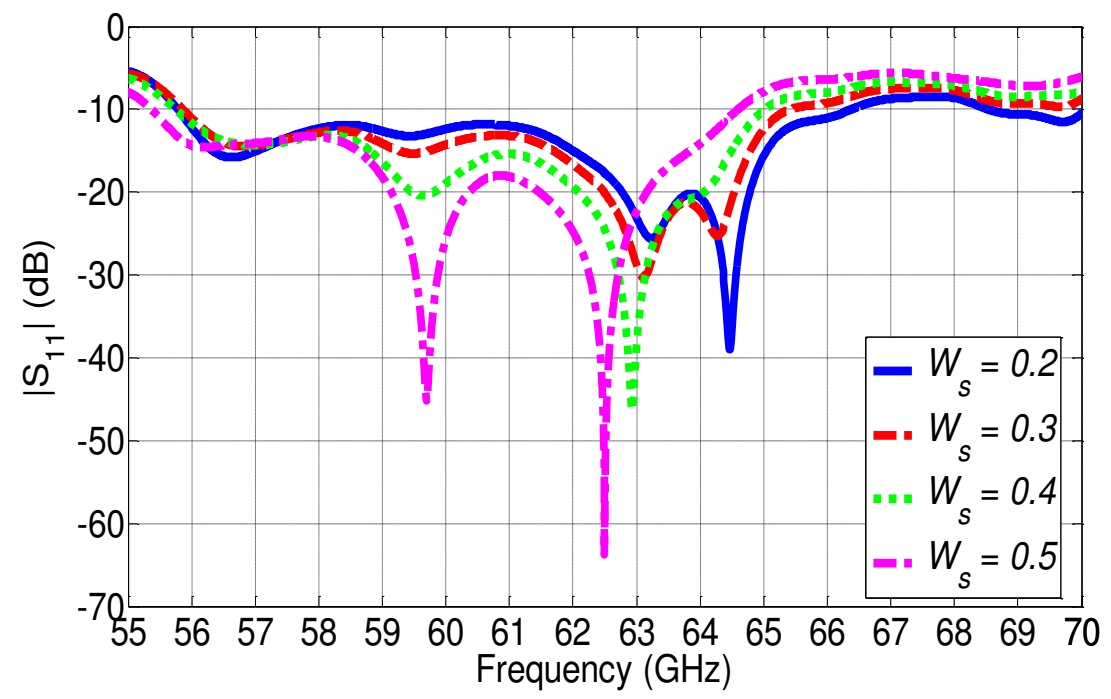

(b)

Fig. 8. Parametric studies on the effect of rectangular slot (a) length $L_{s}$ and (b) width $W_{s}$

\section{Results of novel high-gain CP hybrid antenna}

Compared to the conventional microstrip rectangular patch antenna, installing rectangular DR with inner air grove strongly enhances the axial ratio (AR) bandwidth, realized gain and sidelobe level (SLL). Figure 9 presents the simulated reflection coefficient $S_{11}$ curves of the proposed antenna compared to the conventional patch antenna. The achieved impedance bandwidth ranges from $55.8 \mathrm{GHz}$ to $65.2 \mathrm{GHz}(15.5 \%)$ in case of proposed antenna which is almost the same for the conventional patch antenna except there is a frequency shift towards higher frequency band.

The axial ratio (AR) curves of the proposed antenna compared to the conventional patch antenna are also plotted in Figure 10. It can be seen that the circular polarization bandwidth ( $-3 \mathrm{~dB}$ bandwidth) of the proposed antenna has a dual-band from $58 \mathrm{GHz}$ to $59.2 \mathrm{GHz}$ (about 2\%) and from $60.6 \mathrm{GHz}$ to $62.4 \mathrm{GHz}$ (about 3\%) while it is almost $2.6 \%$ from 57.5 $\mathrm{GHz}$ to $59 \mathrm{GHz}$ in case of conventional patch antenna.

The main advantage of the operation in the $60-\mathrm{GHz}$ frequency band is that it will support gigabit-per-second (Gbps) data rates in wireless communication applications because of large bandwidth. Typical applications demanding Gbps data rates include wireless gigabit Ethernet and wireless uncompressed high-definition (HD) video. For high-gain applications, the $60-\mathrm{GHz}$ frequency band antennas will play important roles in microwave detection and imaging applications.

The simulated realized total gain and SLL for the proposed antenna are shown in Figure 11 and Figure 12, respectively. The curves for the conventional patch antenna are also

Journal of Engineering Sciences, Assiut University, Faculty of Engineering, Vol. 41, No. 3, May, 2013,E-mail address: jes@aun.edu.eg 
O. M. Haraz, Numerical investigations of novel high-gain circularly-polarized hybrid antenna for millimeter-wave detection and imaging applications, pp. 1078 - 1100

plotted for comparison. It can be noticed that the gain is greatly enhanced by at least $3 \mathrm{~dB}$ after using a high-dielectric constant DR with inner air

The realized total gain as a function of frequency as illustrated in Figure 11 shows good characteristics where the gain variation is less than $4 \mathrm{~dB}$ over the frequency range of 56 $\mathrm{GHz}$ to $64 \mathrm{GHz}$. The minimum gain is about $9.5 \mathrm{~dB}$ at $59 \mathrm{GHz}$ while the maximum gain is $13.2 \mathrm{~dB}$ at $56 \mathrm{GHz}$ respectively. The SLL of the antenna radiation pattern is also improved by at least $5 \mathrm{~dB}$ compared to the conventional patch antenna. This may be due to the dielectric lens above the antenna directs the EM propagation into the broadside directions with reducing the SLL and back-lobe radiation.

The simulated radiation patterns along the $x$ - $z$ plane ( $H$-plane) and $y$ - $z$ plane ( $E$-plane) at different frequencies, $56 \mathrm{GHz}, 58 \mathrm{GHz}, 60 \mathrm{GHz}, 62 \mathrm{GHz}$ and $64 \mathrm{GHz}$ are plotted in Figure 13. It can be seen that the gain and sidelobe level are better at lower frequencies, $58 \mathrm{GHz}$ compared to the higher frequencies, $62 \mathrm{GHz}$. This may be due to the antenna is better matched at the lower frequency band compared to the higher frequency band.

From the above simulation results it can be concluded that the proposed hybrid patch DR antenna has an operated bandwidth (reflection coefficient $S_{11}<-10 \mathrm{~dB}$ ) about $15.5 \%$ with a high gain (from $9.5 \mathrm{~dB}$ to $12.3 \mathrm{~dB}$ ) that makes it suitable for various types of millimeterwave communications and millimeter-wave detection and imagining applications.

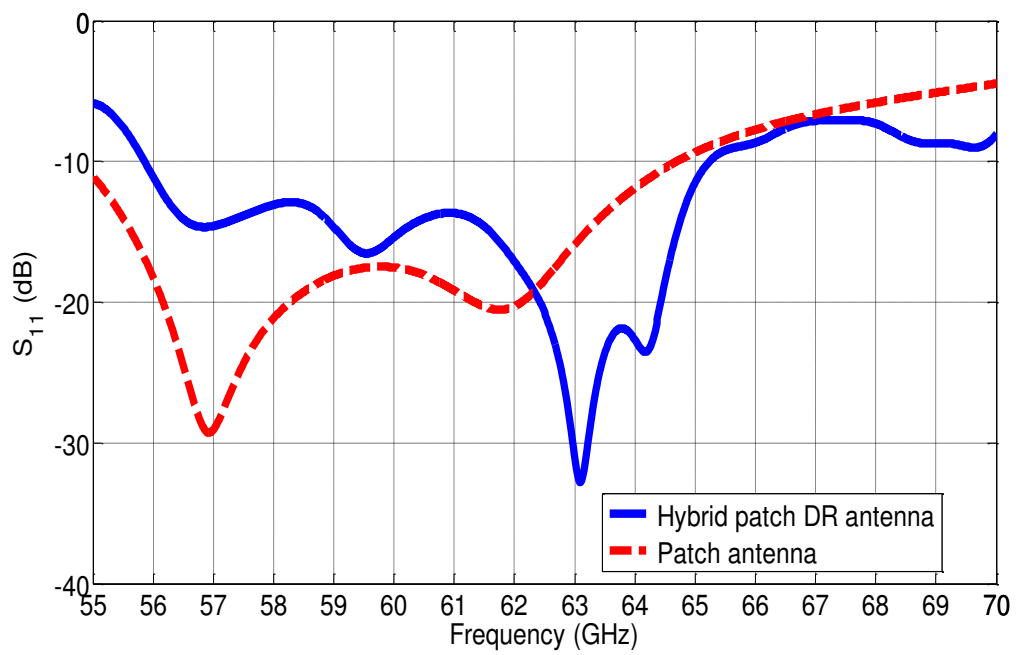

Fig. 9. Simulated reflection coefficient $S_{11}$ curves of the proposed hybrid patch DR antenna.

Journal of Engineering Sciences, Assiut University, Faculty of Engineering, Vol. 41, No. 3, May, 2013,E-mail address: jes@aun.edu.eg 
O. M. Haraz, Numerical investigations of novel high-gain circularly-polarized hybrid antenna for millimeter-wave detection and imaging applications, pp. 1078 - 1100

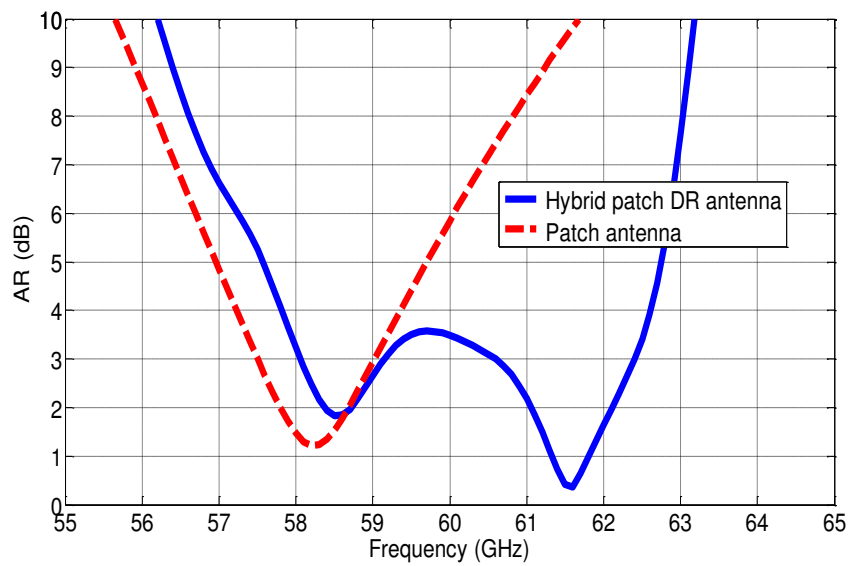

Fig. 10. Simulated axial ratio (AR) curves of the proposed hybrid patch DR antenna.

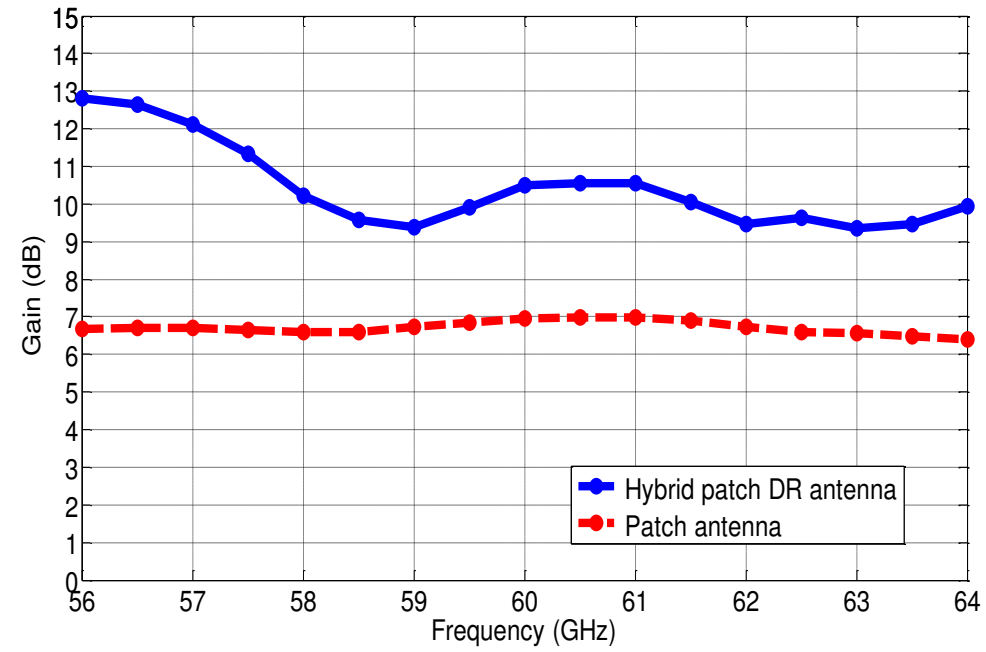

Fig. 11. Simulated realized gain for the proposed hybrid patch DR antenna.

Journal of Engineering Sciences, Assiut University, Faculty of Engineering, Vol. 41, No. 3, May, 2013, E-mail address: jes@aun.edu.eg 
O. M. Haraz, Numerical investigations of novel high-gain circularly-polarized hybrid antenna for millimeter-wave detection and imaging applications, pp. $1078-1100$

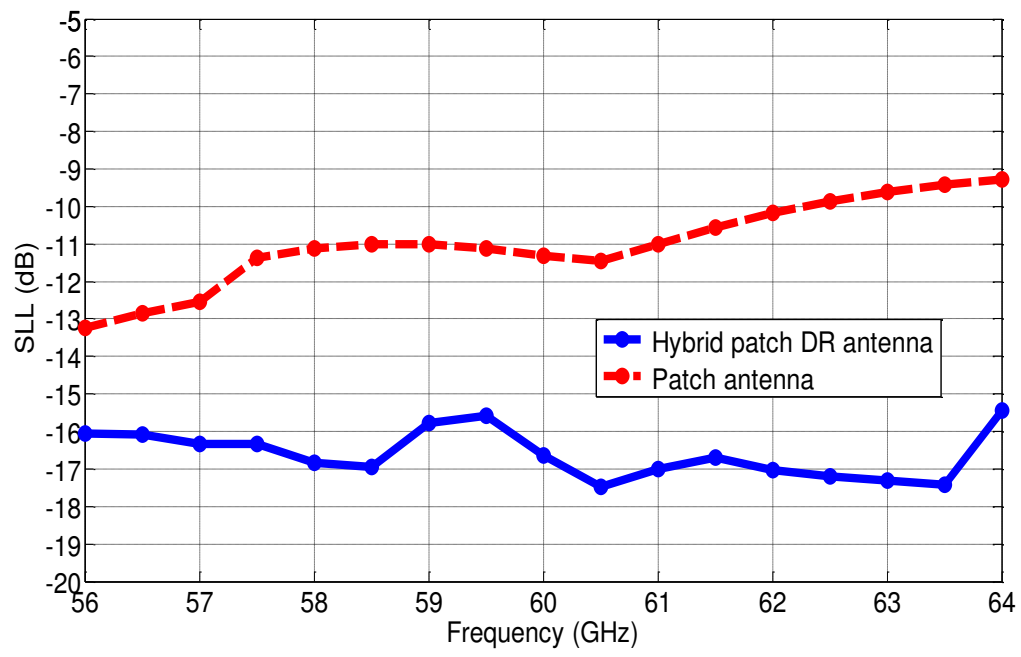

Fig. 12. Simulated Side-lobe level (SLL) for the proposed hybrid patch DR antenna.

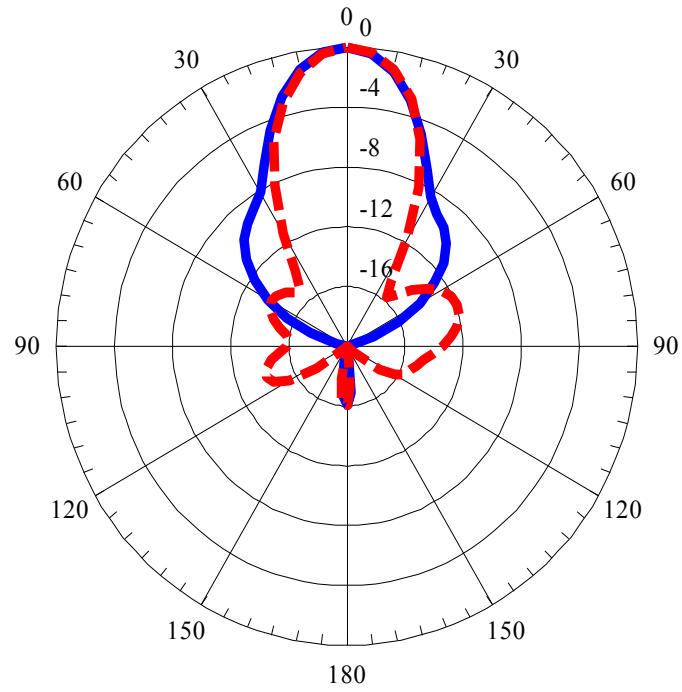

(a)

Journal of Engineering Sciences, Assiut University, Faculty of Engineering, Vol. 41, No. 3, May, 2013,E-mail address: jes@aun.edu.eg 
O. M. Haraz, Numerical investigations of novel high-gain circularly-polarized hybrid antenna for millimeter-wave detection and imaging applications, pp. $1078-1100$

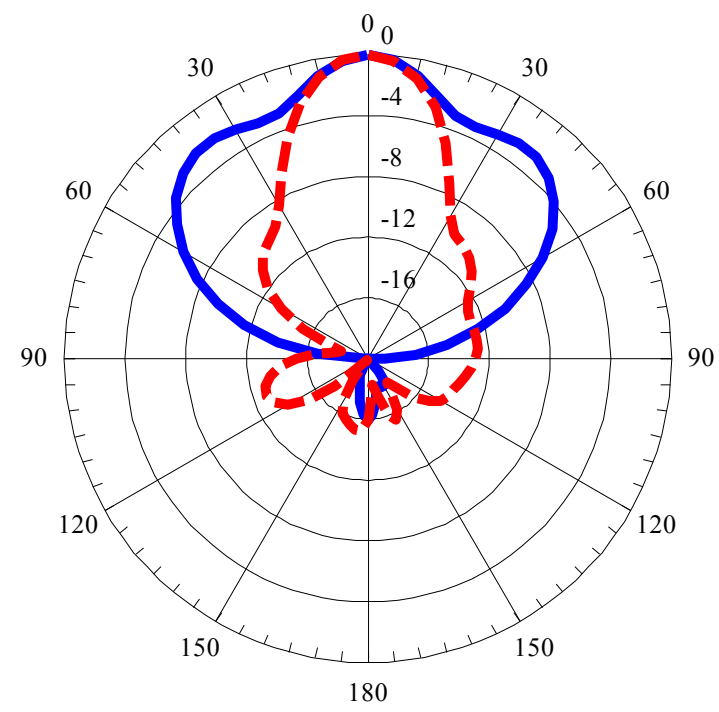

(b)

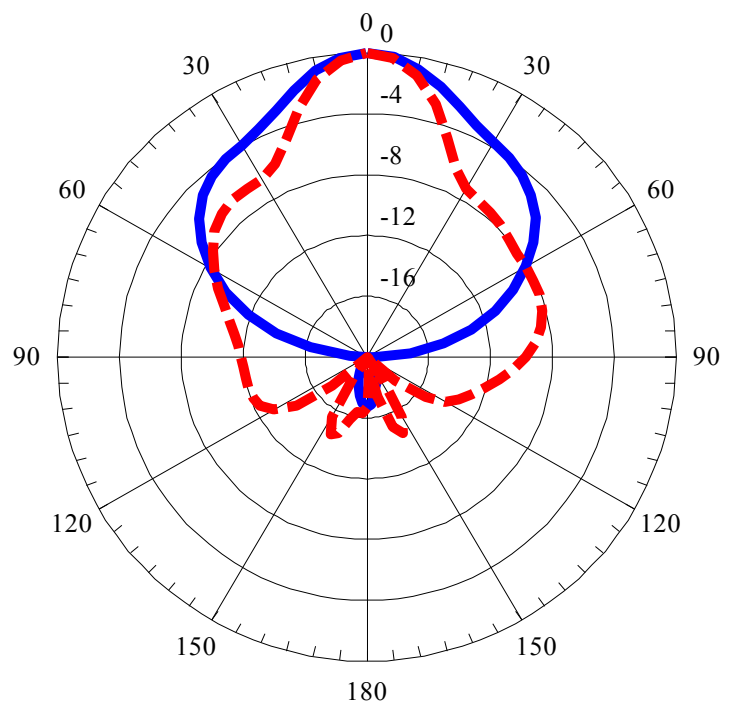

(c)

Journal of Engineering Sciences, Assiut University, Faculty of Engineering, Vol. 41, No. 3, May, 2013,E-mail address: jes@aun.edu.eg 
O. M. Haraz, Numerical investigations of novel high-gain circularly-polarized hybrid antenna for millimeter-wave detection and imaging applications, pp. $1078-1100$

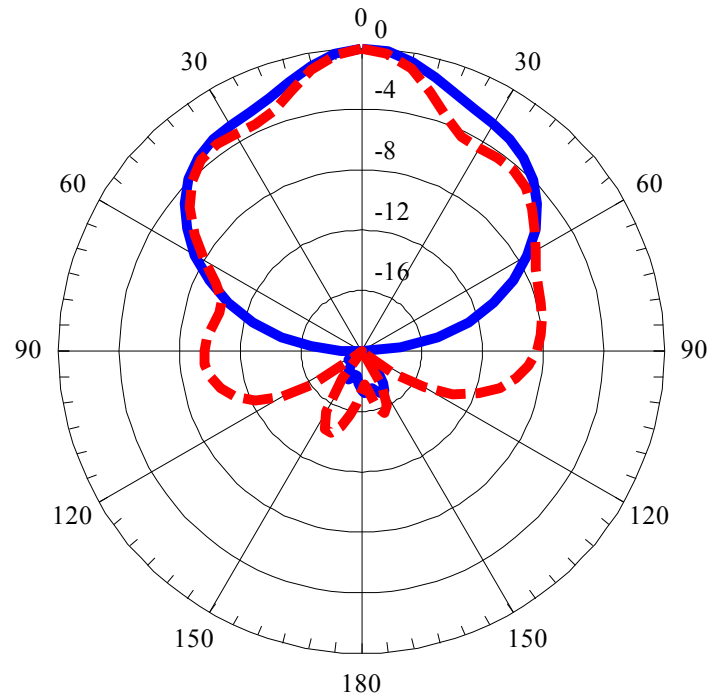

(d)

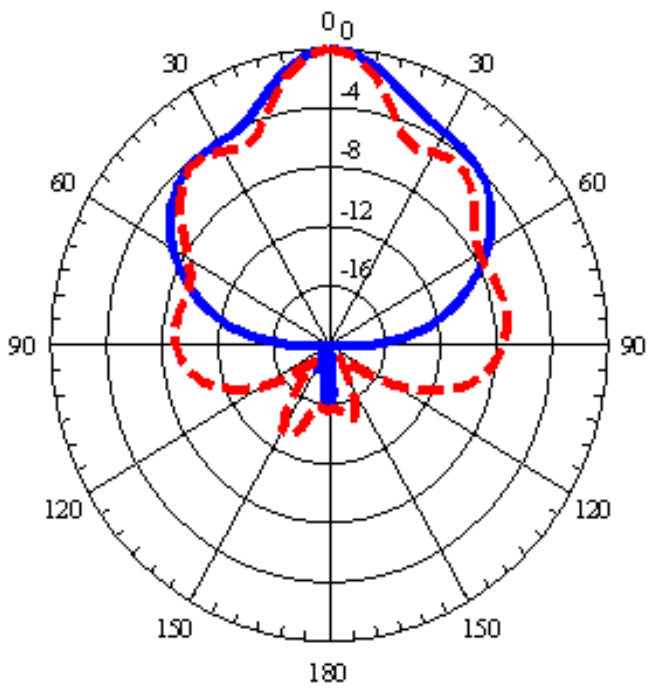

(e)

Fig. 13. Simulated radiation patterns for the proposed hybrid patch DR antenna at (a) 56 $\mathrm{GHz}$, (b) $58 \mathrm{GHz}$, (c) $60 \mathrm{GHz}$, (d) $62 \mathrm{GHz}$ and (e) $64 \mathrm{GHz}$.(Blue solid line for $H$-plane and red dashed line for $E$-plane).

Journal of Engineering Sciences, Assiut University, Faculty of Engineering, Vol. 41, No. 3, May, 2013,E-mail address: jes@aun.edu.eg 
O. M. Haraz, Numerical investigations of novel high-gain circularly-polarized hybrid antenna for millimeter-wave detection and imaging applications, pp. $1078-1100$

\section{Proposed improved high-gain cp hybrid antenna}

Compared to the conventional patch and hybrid patch DR antennas, installing a highdielectric constant dielectric lens of a hemispherical shape above the proposed circularlypolarized high gain hybrid patch DR antenna, the antenna characteristics such as the axial ratio (AR) bandwidth, realized gain and sidelobe level (SLL) have been improved. The proposed antenna geometry is shown in Figure 14. The simulated reflection coefficient $\left|S_{11}\right|$ curves of the proposed antenna compared to the previous two antenna designs are shown in Figure 15. The achieved impedance bandwidth ranges from $56.9 \mathrm{GHz}$ to $64.1 \mathrm{GHz}$ (11.9\%) in case of proposed hybrid patch DR antenna with dielectric lens which is less than that for the previous antenna designs.

The axial ratio (AR) curves of the proposed hybrid patch DR antenna with dielectric lens compared to the previous antenna designs are also plotted in Figure 16. It can be seen that the $-3 \mathrm{~dB}$ axial ratio bandwidth of the proposed antenna is decreased to about $1.93 \%$ from $61.45 \mathrm{GHz}$ to $62.65 \mathrm{GHz}$ while it is dual-band from $58 \mathrm{GHz}$ to $59.2 \mathrm{GHz}$ (about 2\%) and from $60.6 \mathrm{GHz}$ to $62.4 \mathrm{GHz}$ (about 3\%).

The simulated realized total gain as a function of frequency as illustrated in Figure 17 shows good characteristics where the gain variation is less than $3 \mathrm{~dB}$ over the frequency range of $56 \mathrm{GHz}$ to $64 \mathrm{GHz}$. The curves for the previous antenna designs are also plotted for comparison. The minimum gain is about $10.5 \mathrm{~dB}$ at $59 \mathrm{GHz}$ while the maximum gain is $13.5 \mathrm{~dB}$ at $62.5 \mathrm{GHz}$, respectively. It can be noticed that the gain is enhanced by at least 2 $\mathrm{dB}$ at $60 \mathrm{GHz}$ after using a high-dielectric constant dielectric lens on the top of hybrid patch DR antenna.

Table 2.

Antenna characteristics at $60 \mathrm{GHz}$

\begin{tabular}{|c|c|c|c|}
\hline \multirow[b]{2}{*}{ Parameters } & \multicolumn{3}{|c|}{ Antenna characteristics @ $60 \mathrm{GHz}$} \\
\hline & $\begin{array}{l}\text { Conventional } \\
\text { Patch Antenna }\end{array}$ & $\begin{array}{c}\text { Hybrid Patch DR } \\
\text { Antenna }\end{array}$ & $\begin{array}{c}\text { Hybrid Antenna } \\
\text { with Dielectric } \\
\text { Lens }\end{array}$ \\
\hline$S 11$ & $-18 d B$ & $-15 d B$ & $-17 d B$ \\
\hline $\begin{array}{c}S 11 B W \\
\text { (bandwidth) }\end{array}$ & $\begin{array}{c}55.0-64.5 \mathrm{GHz} \\
(9.5 \mathrm{GHz}, 15.9 \%)\end{array}$ & $\begin{array}{c}55.8-65.2 \mathrm{GHz} \\
(9.4 \mathrm{GHz}, 15.5 \%)\end{array}$ & $\begin{array}{c}56.9-64.1 \mathrm{GHz} \\
(7.2 \mathrm{GHz}, 11.9 \%)\end{array}$ \\
\hline Gain & $5.8 d B i$ & $9.0 d B i$ & $12.5 d B i$ \\
\hline $\begin{array}{c}\text { Total } \\
\text { efficiency } \eta\end{array}$ & $88 \%$ & $84 \%$ & $94 \%$ \\
\hline$S L L$ & $\begin{array}{c}E \\
-9.1 d B\end{array}$ & $\begin{array}{c}E \\
-6.8 d B\end{array}$ & $\begin{array}{cc}E & H \\
-11.9 d B & -19.3 d B\end{array}$ \\
\hline
\end{tabular}

Journal of Engineering Sciences, Assiut University, Faculty of Engineering, Vol. 41, No. 3, May, 2013, E-mail address: jes@aun.edu.eg 
O. M. Haraz, Numerical investigations of novel high-gain circularly-polarized hybrid antenna for millimeter-wave detection and imaging applications, pp. $1078-1100$

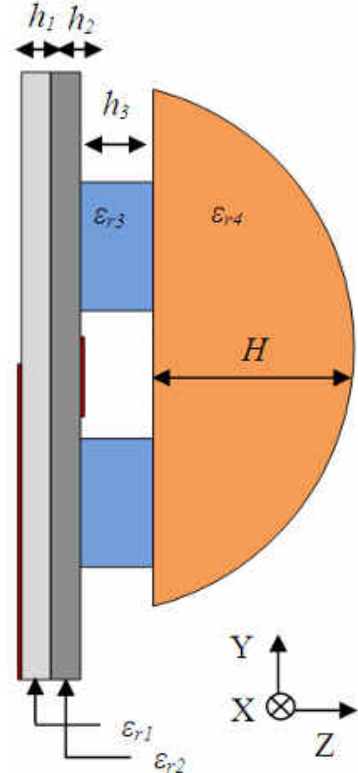

(a)

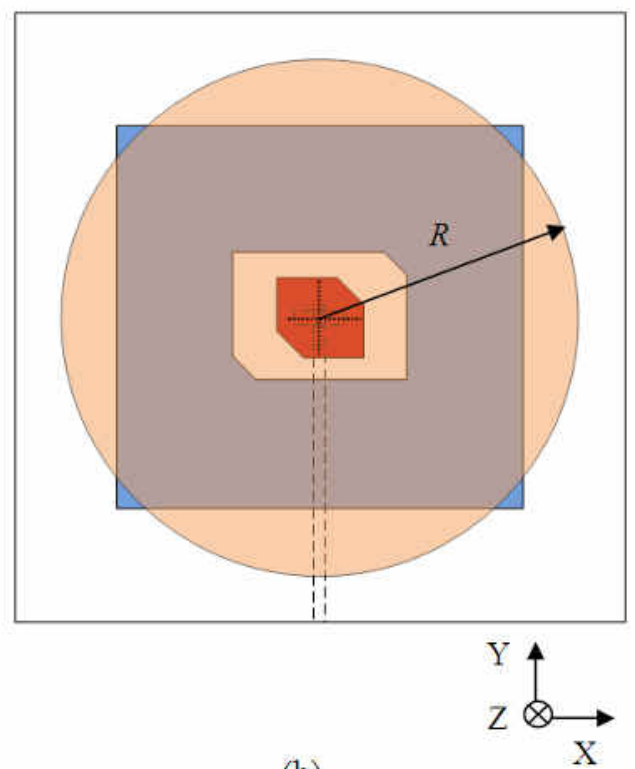

(b)
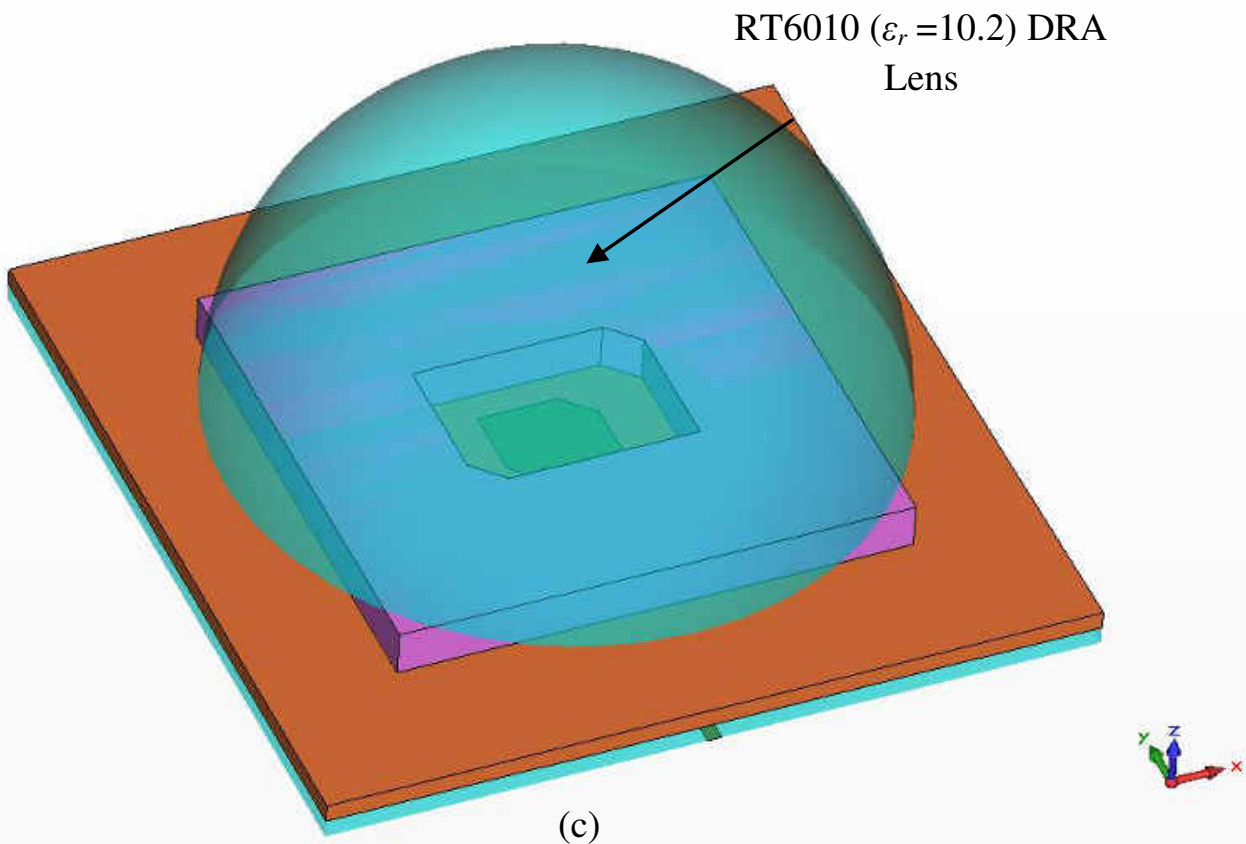

Fig. 14. Geometry of the proposed improved high-gain $\mathrm{CP}$ antenna with dielectric lens (a) side-view (b) top-view (c) three-dimensional isometric view.

Journal of Engineering Sciences, Assiut University, Faculty of Engineering, Vol. 41, No. 3, May, 2013, E-mail address: jes@aun.edu.eg 
1095

O. M. Haraz, Numerical investigations of novel high-gain circularly-polarized hybrid antenna for millimeter-wave detection and imaging applications, pp. 1078 - 1100

The side-lobe level (SLL) for the proposed antenna is shown in Figure 18. The curves for the previous antenna designs are also plotted for comparison. The SLL of the antenna radiation pattern is also improved by at least $3 \mathrm{~dB}$ at $60 \mathrm{GHz}$ compared to the hybrid patch DR antenna. It can be seen that the gain and sidelobe level are better at lower frequencies, i.e. $58 \mathrm{GHz}$ compared to the higher frequencies, i.e. $62 \mathrm{GHz}$. This is may be because the antenna is better matched at the lower frequency band compared to the higher frequency band.

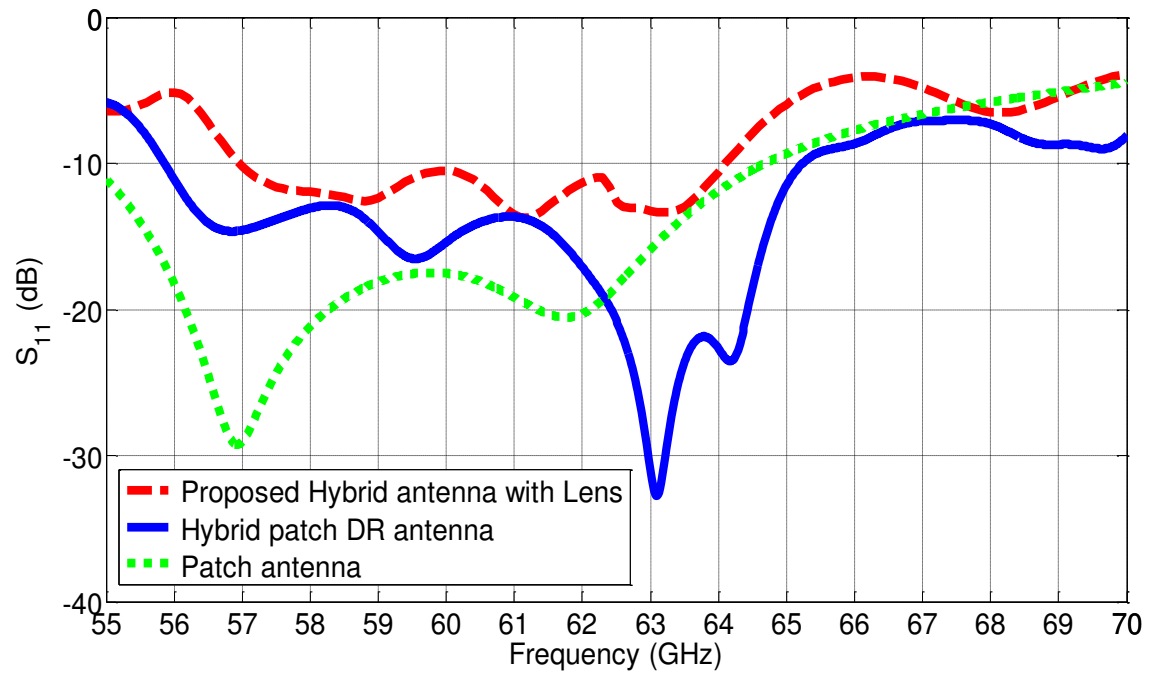

Fig. 15. Simulated reflection coefficient $S_{11}$ curves of the proposed improved highgain antenna.

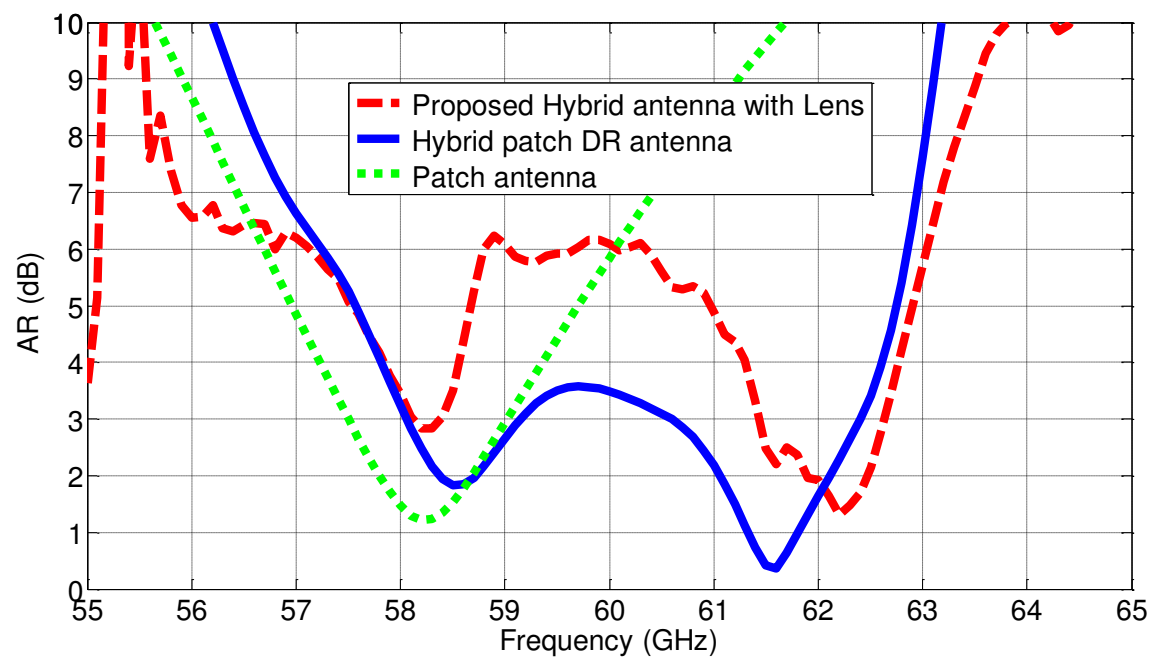

Fig. 16. Simulated axial ratio (AR) curves of the proposed improved high-gain antenna.

Journal of Engineering Sciences, Assiut University, Faculty of Engineering, Vol. 41, No. 3, May, 2013,E-mailaddress: jes@aun.edu.eg 
O. M. Haraz, Numerical investigations of novel high-gain circularly-polarized hybrid antenna for millimeter-wave detection and imaging applications, pp. $1078-1100$

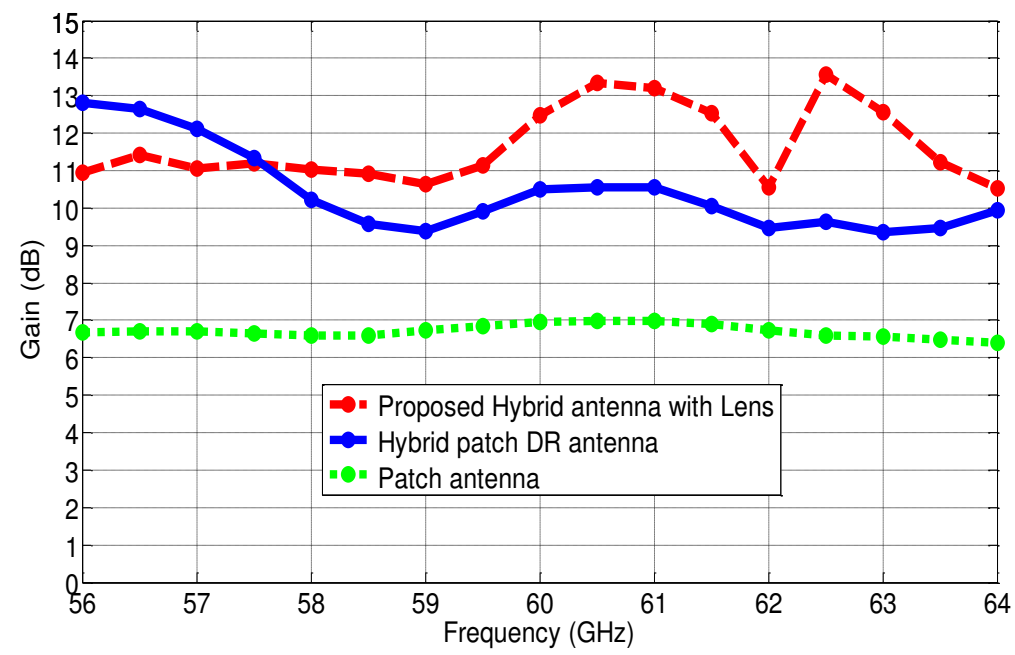

Fig. 17. Simulated realized gain for the proposed improved high-gain antenna.

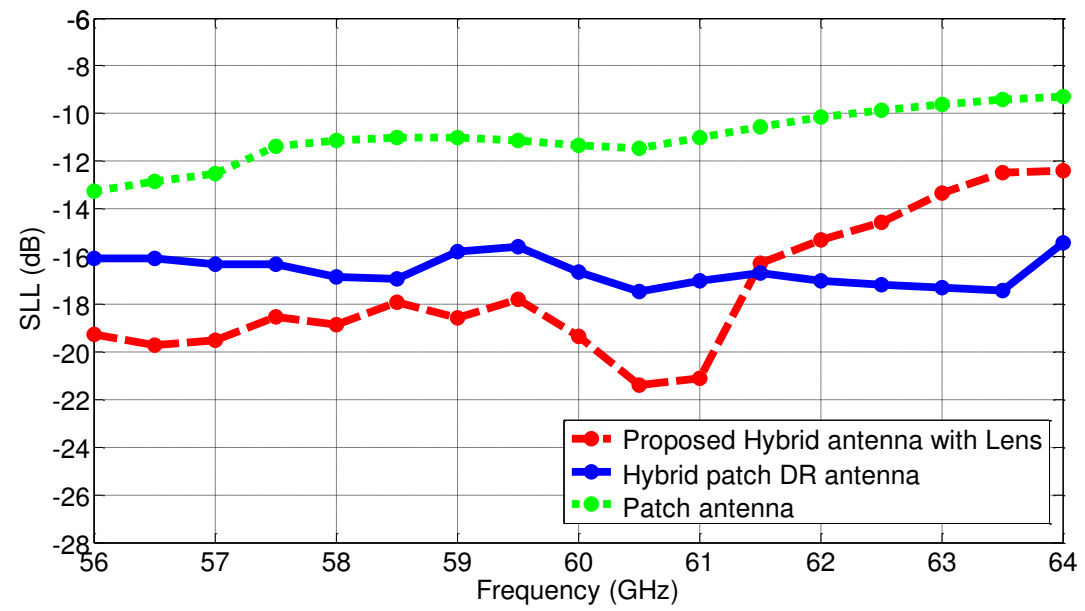

Fig. 18. Simulated Side-lobe level (SLL) for the proposed improved high-gain antenna.

The simulated radiation patterns along the $x$ - $z$ plane ( $H$-plane) and $y$ - $z$ plane ( $E$-plane) at different frequencies, i.e. $56 \mathrm{GHz}, 58 \mathrm{GHz}, 60 \mathrm{GHz}, 62 \mathrm{GHz}$ and $64 \mathrm{GHz}$ are plotted in Figure 19.

Journal of Engineering Sciences, Assiut University, Faculty of Engineering, Vol. 41, No. 3, May, 2013,E-mail address: jes@aun.edu.eg 
O. M. Haraz, Numerical investigations of novel high-gain circularly-polarized hybrid antenna for millimeter-wave detection and imaging applications, pp. $1078-1100$

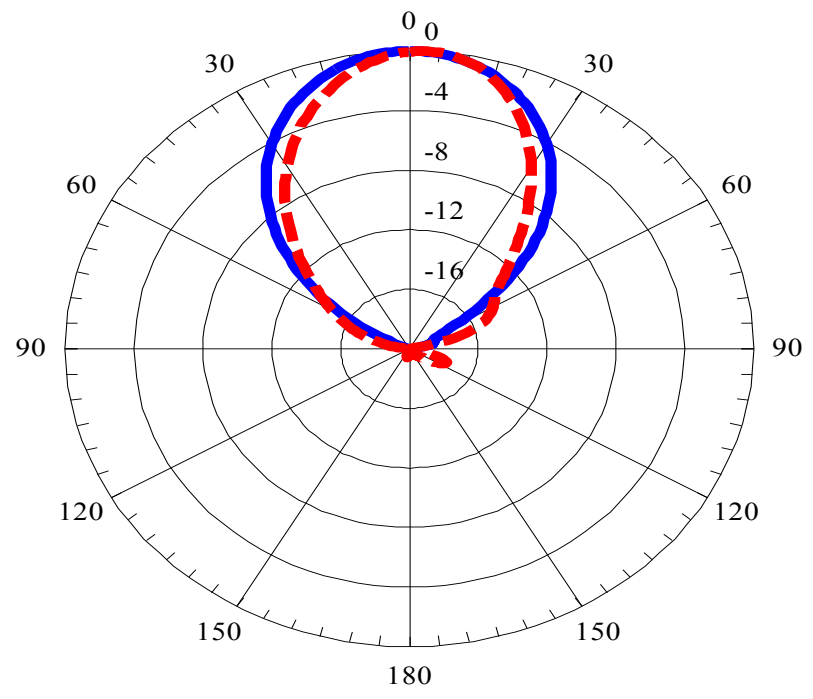

(a)

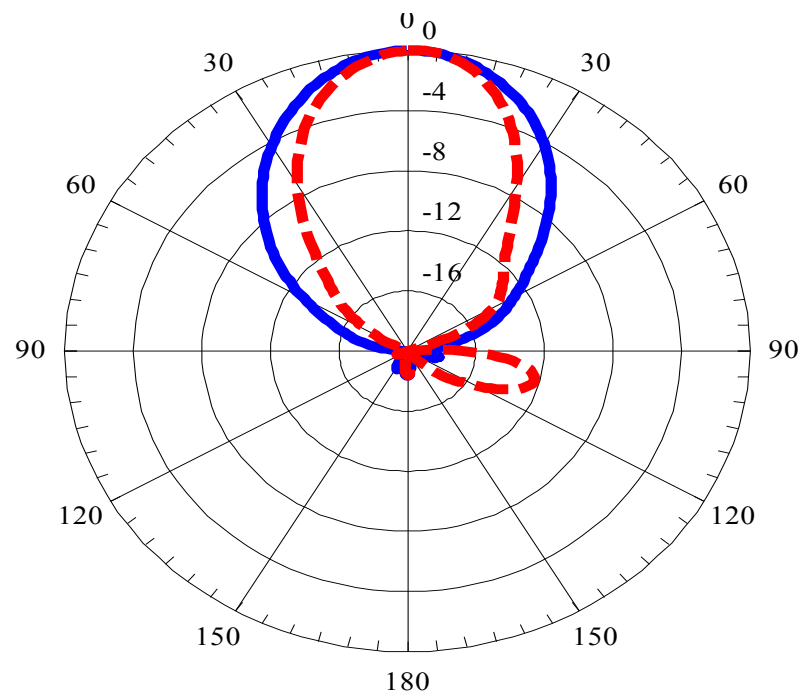

(b)

Journal of Engineering Sciences, Assiut University, Faculty of Engineering, Vol. 41, No. 3, May, 2013,E-mail address: jes@aun.edu.eg 
O. M. Haraz, Numerical investigations of novel high-gain circularly-polarized hybrid antenna for millimeter-wave detection and imaging applications, pp. $1078-1100$

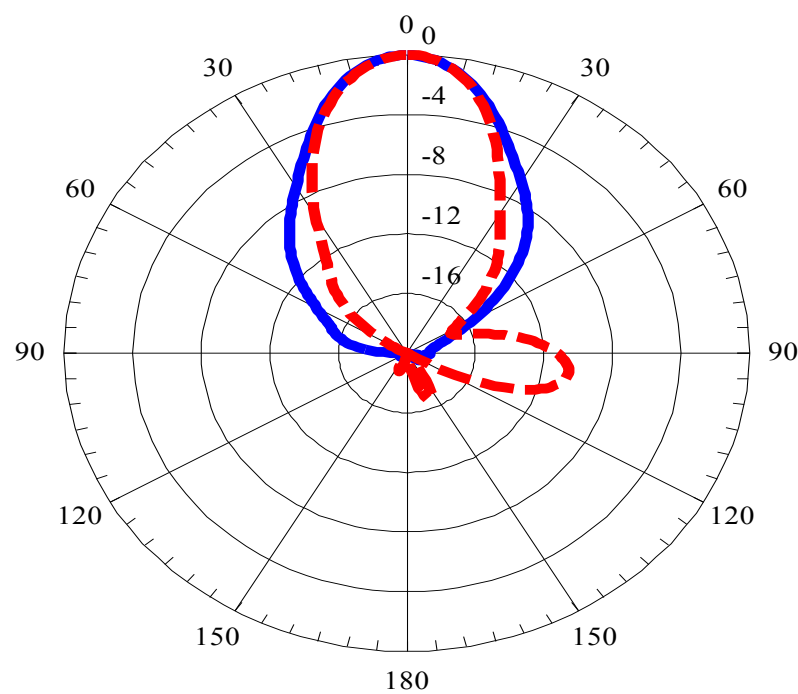

(c)

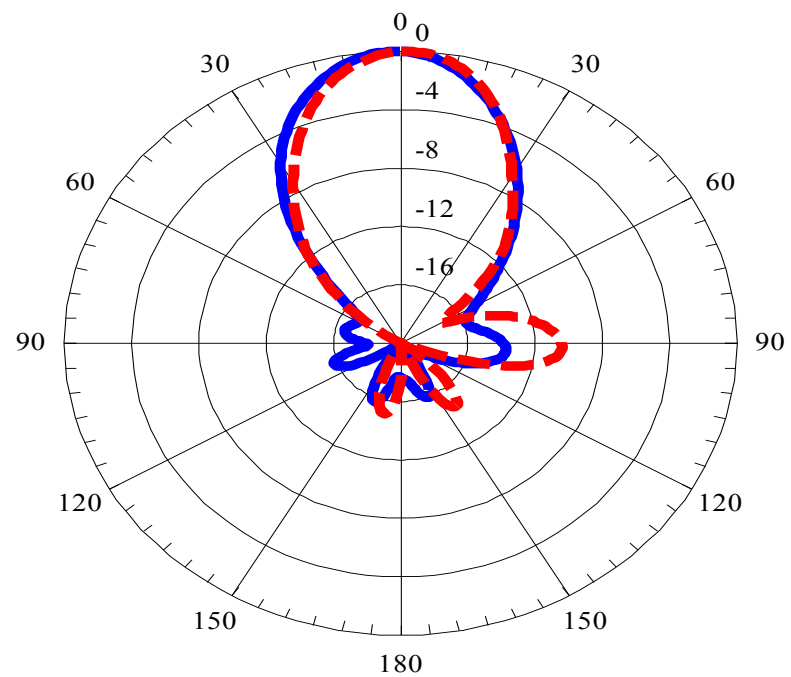

(d)

Journal of Engineering Sciences, Assiut University, Faculty of Engineering, Vol. 41, No. 3, May, 2013,E-mail address: jes@aun.edu.eg 


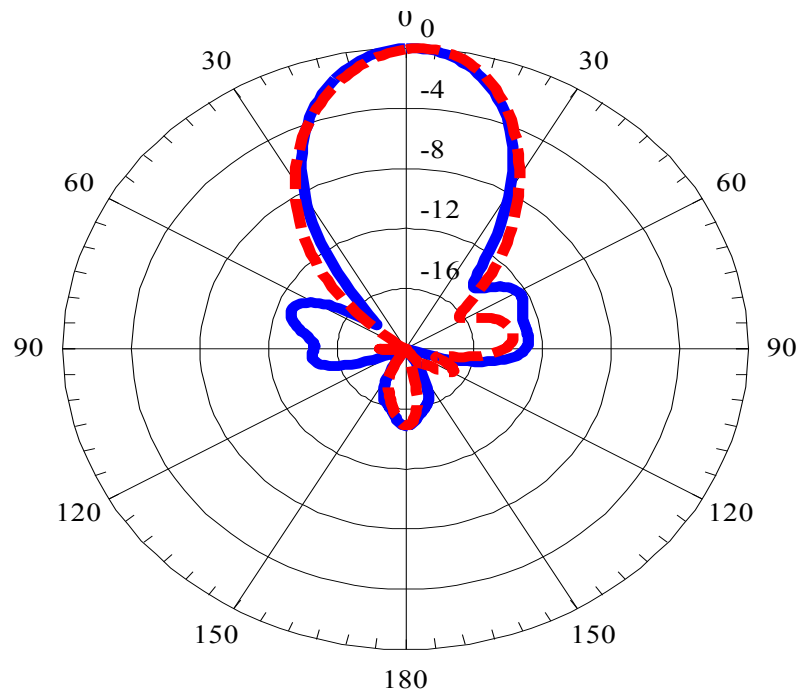

(e)

Fig. 19. Simulated radiation patterns for the proposed antenna at (a) $56 \mathrm{GHz}$, (b) 58 $\mathrm{GHz}$, (c) $60 \mathrm{GHz}$, (d) $62 \mathrm{GHz}$ and (e) $64 \mathrm{GHz}$.(Blue solid line for $H$-plane and red dashed line for $E$-plane).

\section{Conclusions}

In this paper a novel circularly-polarized high gain dielectric resonator (DR)/microstrip antenna is proposed. The proposed antenna has an operated bandwidth (reflection coefficient $\left|\mathrm{S}_{11}\right|<-10 \mathrm{~dB}$ ) about $15.5 \%$ with a high gain (from $9.5 \mathrm{~dB}$ to $12.3 \mathrm{~dB}$ ) that makes it suitable for various types of millimeter-wave communications and millimeterwave detection and imagining. Circular polarization is obtained by modifying both of the corner shapes of radiator and the DRA. Antenna feeding is achieved by using single microstrip line with a rectangular aperture in the ground plane. The proposed antenna has improved axial ratio (AR) bandwidth, realized gain and sidelobe level (SLL) compared to the microstrip rectangular patch antenna only. For further gain and radiation characteristics enhancement, a hemi-spherical dielectric lens made of a high-dielectric constant material is installed above the proposed antenna.

\section{References}

[1] B. A. Harvey, D. H. Howard, E. N. Barnhart, F. G. Loso and J. A. Staba, "An Analysis of MMW Wireless LANs For LPVAJ Command Post Communications", Military Communications Conference, MILCOM '93. Conference record, pp. 580-584, 1993.

[2] A. Elboushi and A.-R. Sebak, "High-Gain Hybrid Microstrip/Conical Horn Antenna for MMW Applications,” Antenna Wireless Propag. Lett., vol. 11, pp. 129 - 132, 2012.

[3] A. M. Elboushi, O. Ahmed, A.-R. Sebak, T. A. Denidni, "A New Circularly Polarized High Gain DRA Millimeter-Wave Antenna", IEEE International Symposium on Antennas and

Journal of Engineering Sciences, Assiut University, Faculty of Engineering, Vol. 41, No. 3, May, 2013,E-mail address: jes@aun.edu.eg 
O. M. Haraz, Numerical investigations of novel high-gain circularly-polarized hybrid antenna for millimeter-wave detection and imaging applications, pp. $1078-1100$

Propagation and CNC/USNC/URSI Radio Science Meeting (AP-S/URSI), Toronto, Canada July 11-17, 2010.

[4] A. Perron, T. A. Denidni, A.-R. Sebak, "High-Gain Hybrid Dielectric Resonator Antenna for Millimeter-Wave Applications: Design and Implementation", Antennas and Propagation, IEEE Transactions on Volume 57, Issue 10, Part 1, pp. 2882 - 2892, Oct. 2009.

[5] A. Perron, T. A. Denidni, A.-R. Sebak, "A Low-Cost and High-Gain Dual-Polarized Wideband Millimeter-Wave Antenna"; Antennas and Propagation, EuCAP European Conference. pp. 3558 - 3561, Berlin, Germany, 2009Summary: This paper introduces a novel dual-fed dual-polarized antenna for millimeter-wave applications. Both a very large impedance bandwidth $(11.33 \mathrm{GHz}$ ) and a high gain (peak value of $12.9 \mathrm{~dB}$ ) are achieved with a simple low-cost hybrid configuration. The is......

[6] T. A. Denidni and Q. Rao, "Hybrid dielectric resonator antennas with radiating slot for dual frequency operation," Antenna Wireless Propag. Lett., vol. 3, no. 1, pp. 321-323, 2004.

[7] J. A. G. Akkermans, M. H. A. Herben, "Millimeter-Wave Antenna With Adjustable Polarization", Antennas and Wireless Propagation Letters, IEEE Volume 7, pp.539 - 542, 2008.

[8] T. Ke-jun; L. Xiu-zhen, "Millimeter wave circularly polarized substrate integrated waveguide antenna", ICMMT 2008. Volume 3, pp.1058 - 1061, April 2008.

[9] CST@ Microwave Studio, version2006B.02.

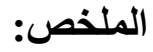

تحقيقـات عدديـة لهـو ائي هجين جديـد ذو كسـب عـالي و اسـتقطاب دائر بي لتطبيقـات الكثـف و التصـوير

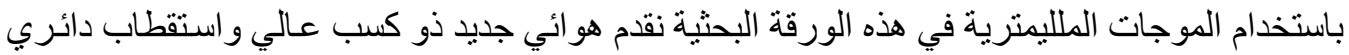
لتطبيقات الموجات الملليمنرية (MMW) ـ الهو ائي المقترح يتكون من عنصر مشع ذو شكل مستطيل تم

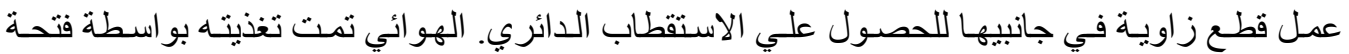

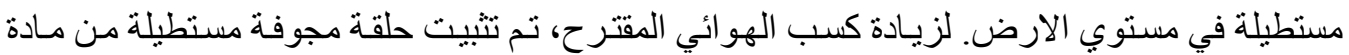

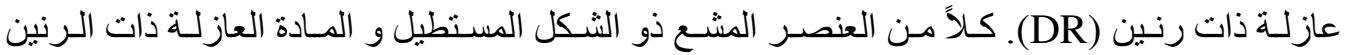

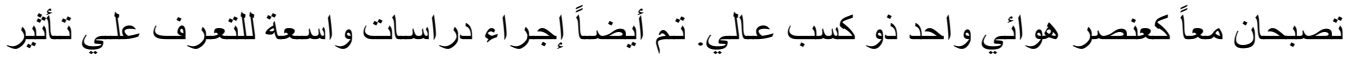
تغيير خصائص الهوائي على عرض نطاق التردد. لمزيد من تعزيز الكسب، تم تثبيت ــ أعلي الهوائي

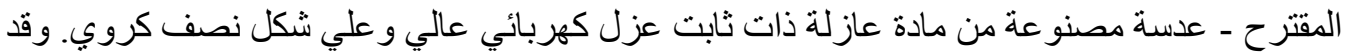

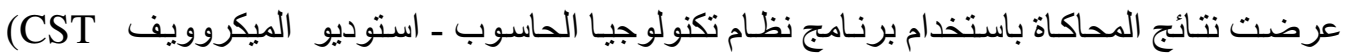

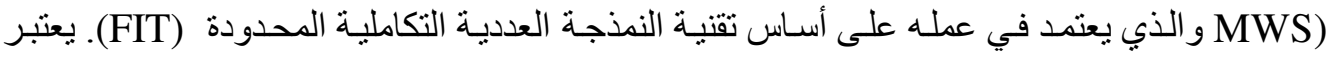

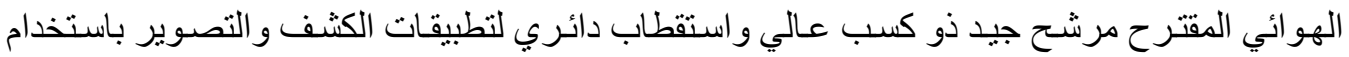
الموجات الملليمترية.

Journal of Engineering Sciences, Assiut University, Faculty of Engineering, Vol. 41, No. 3, May, 2013, E-mail address: jes@aun.edu.eg 